\title{
A SAFE AND ECONOMICAL METHOD OF ADMINISTERING FLUOTHANE IN CLOSED CIRCUIT ANAESTHESIA ${ }^{1}$
}

\section{A. Romagnoli, M.D., M. Cohen, M.D., and M. J.,Diamond, M.в., Ch.в."}

Since Fluothane was discovered by Raventos ( $1-4$ ) in 1956 a score of papers have appeared in the medical press, all seeking the least expensive and most accurate method of delivering this potent and very expensive agent in closed circuit anaesthesia (5-8).

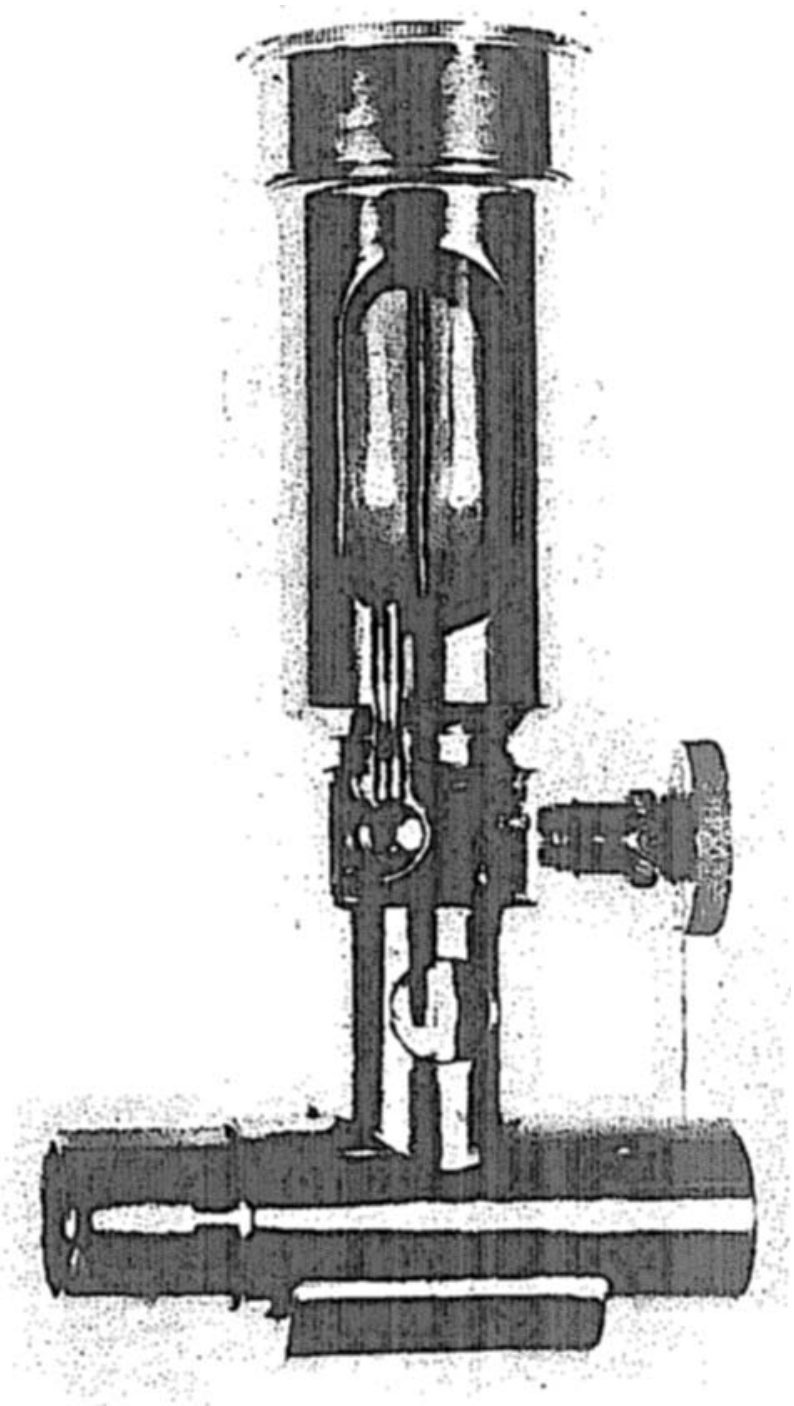

Figure 1

We, too, decided to seek a solution to this problem, and.found that as Macintosh (9) suggested: "Probably the most accurate method of administering the vapour of a liquid anaesthetic in any desired concentration is to volatilize a calculated volume of the liquid in a known volume of air and to deliver the resultant

1 Presented at the Canadian Anaesthetists' Society Annual Meeting, Montebello, P.Q., Mily, 1959.

2From the Denartment of Anaesthesia, Jewish General Hospital, Montreal, P.Q. 


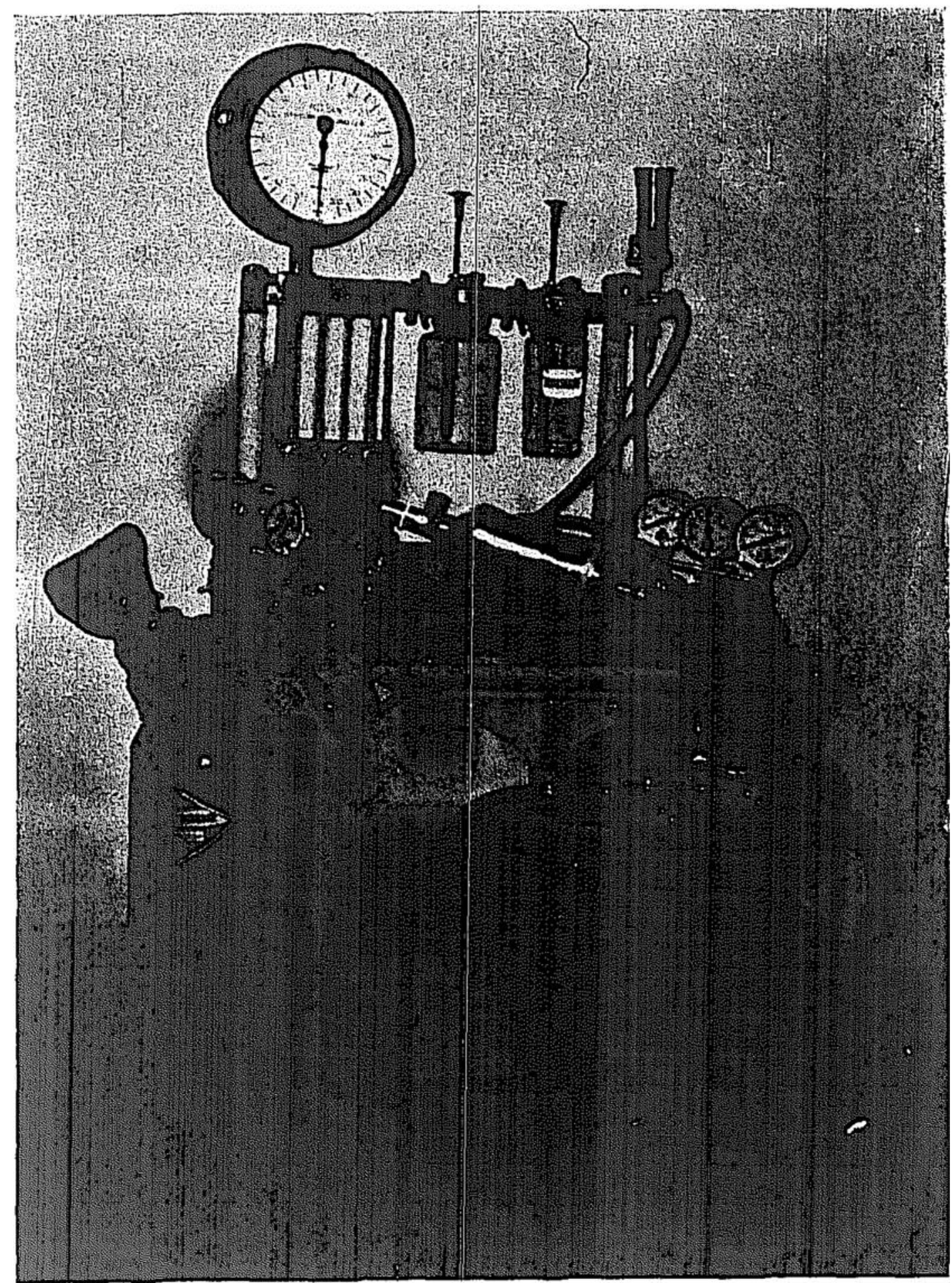

Figure 2

mixture to the patient. This method was used in animal experiments a hundred years ago by Snow and later was employed clinically by Clover." We have used a method based on this theory to administer Fluothane safely and economically in closed or semi-closed circuit anaesthesia. As a means of calculating accurate and minute amounts of the anaesthetic in question, we have availed ourselves of the Goldman's drip feed, an apparatus known particularly well to the British anaesthetist (Fig. 1). It is composed of a bottle containing the liquid anaesthetic, a dripping chamber below, connected to the bottle by a capillary tube and a needle valve which regulates the flow down to one or two drops per minute. The only modification which we made to this was the addition of a gauze wick in thelumen of the tube where the gases flow, immediately below the dripping chamber, so as to increase the vapourization of the Fluothane (Fig. 2). This apparatus is very versatile and fits most ariaesthetic machines. 
The Goldman's drip feed delivers 150 drops per cubic centimetre. To calculate the volume to volume concentration of Fluothane in the gaseous mixture, we used this formula:

$$
\frac{V S G}{M W} \cdot 22.4 \text { L. (N.T.P.) }
$$

corrected for temperature and pressure, respectively $25^{\circ} \mathrm{C}$., and $75.5 \mathrm{~cm}$. $/ \mathrm{Hg}$. Where $V$ is the volume in drops of liquid vapourized per minute; $S G$ the specific gravity of Fluothane; MW the molecular weight of Fluothane and $22.4 \mathrm{~L}$., according to Avogadro's law is the volume of vapour produced by $1 \mathrm{gm}$. molecule of

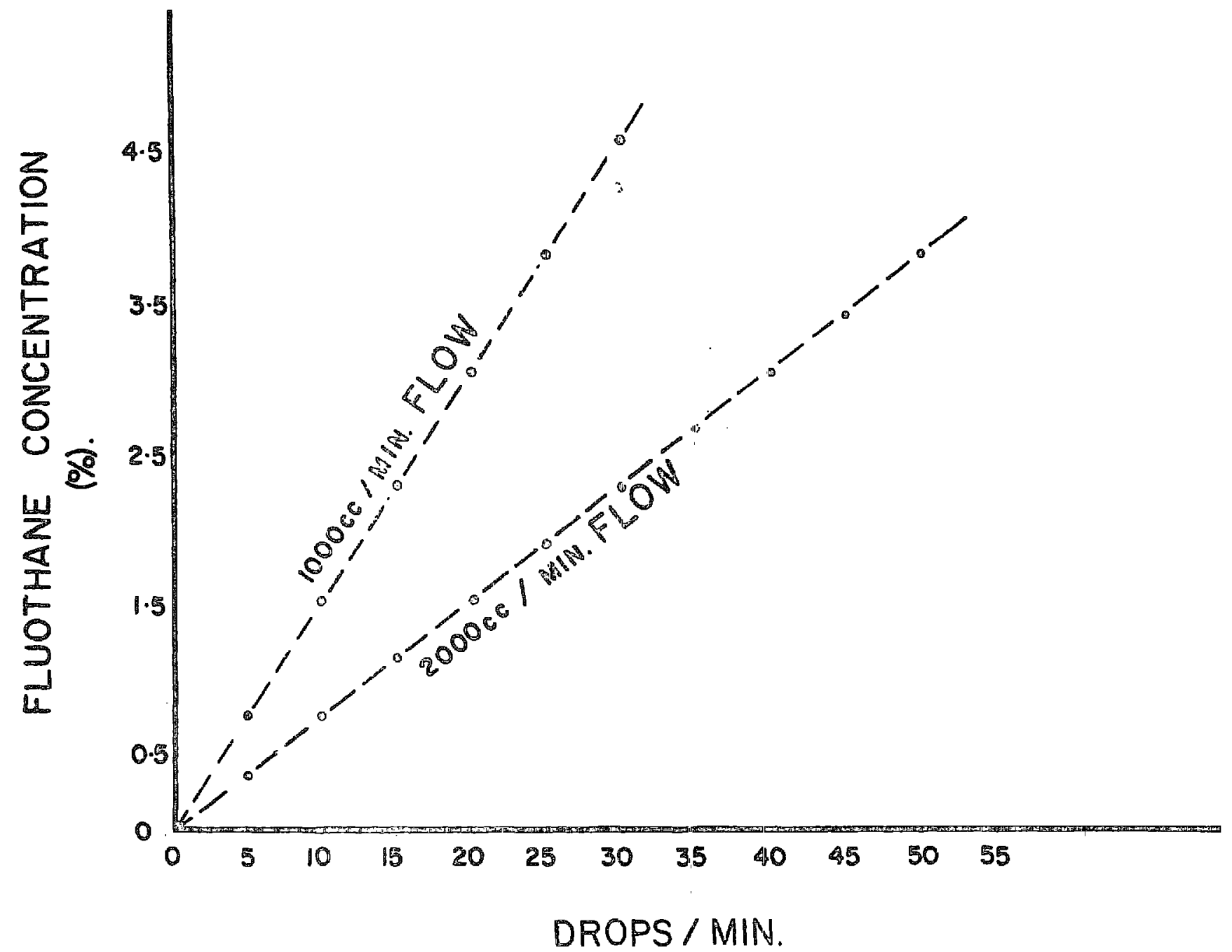

FIGURE 3

substance at N.T.P. The developed formula gave us $211 \mathrm{cc}$. of Fluothane vapour. In the practice of this method, it is advantageous to remember that 7.5 drops are equal to $0.05 \mathrm{cc}$. and to $10 \mathrm{cc}$. of vapour. Therefore, by adjusting the rate of drip in a known and constant flow of gas the volume to volume percentage is clear and accurate. This calculation can be seen on the diagram (Fig. 3) which we have made. On the abscissa, one reads the drops per minute and, on the ordinate, the $\mathrm{v} / \mathrm{v}$ percentage. We have traced only $2,000 \mathrm{cc}$. and $1,000 \mathrm{cc}$. flows, but the method applies just as simply to any other flow above or below these figures. Moreover, we stress that this method is just as safe and accurate in total rebreathing as it is in any degree of partial rebreathing. 
During the past two years there were well over 6,000 administrations of Fluothane at our hospital, 809 of which were done by this method. The patients varied i age from 10 to 83 years. The distribution of these cases by type of operation demonstrates the fact that they were all major ones:

$\begin{array}{lr}\text { Intrathoracic operations } & 4 \\ \text { Biliary tract operations } & 154 \\ \text { Bowel resections } & 73 \\ \text { Gastrectomies } & 63 \\ \text { Upper laparotomies } & 23 \\ \text { Lower laparotomies } & 81 \\ \text { Appendectomies } & 72 \\ \text { Intra-abdominal gynaecological operations } & 74 \\ \text { Kidney operations } & 35 \\ \text { Sympathectomies } & 9 \\ \text { Hernias } & 36 \\ \text { Prostatectomies } & 35 \\ \text { Mastectomies } & 33 \\ \text { Thyroidectomies } & 16 \\ \text { Orthopaedic operations } & 62 \\ \text { E.N.T. operations } & 7 \\ \text { Others } & 32 \\ \quad \quad \text { ToTAL } & 809\end{array}$

We need only add here that of the four intrathoracic operations, two were mitral valvulotomies and two were lung resections. The distribution of cases by time gives a total of 1,598 anaesthetic hours, and shows that many were lengthy procedures -491 being two hours or more:

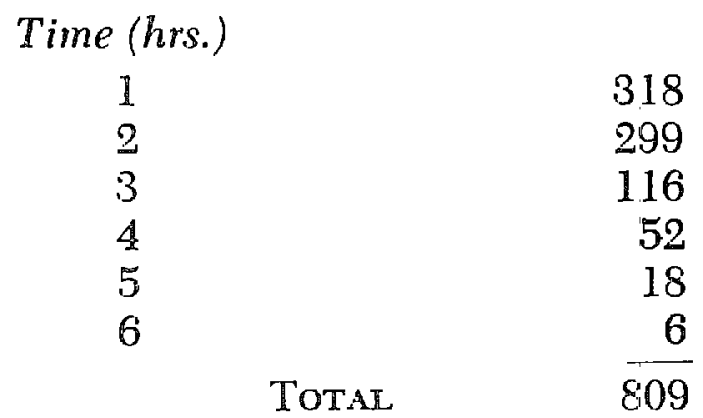

In this series there were no deaths or complications which could be attributed to the anaesthetic or the method. The patients fared well in spite of the fact that some were acutely ill. These few facts demonstrate clearly the safety and the reliability of this method.

As to the economy, we can only say that, by means of this type of administration, the expenditure for Fluothane is $48 \phi$ per hour delivering 7.5 drops per minute (the equivalent of 1.05 per cent in a $1 \mathrm{~L}$. flow). In addition, the Goldman's drip feed is very inexpensive.

\section{SURMAary}

A new method of administering Fluothane in closed circuit anaesthesia is presented. The Goldman's drip feed is used to measure minute amounts of the 
drug accurately. In all, 809 cases were done. The simplicity and safety of the method are stressed, together with its economy.

\section{REFERENCES}

1. Raventos, J. Abstracts of Communications. Tweritieth International Phy'siological Congress. P. $754(1956)$.

2. Raventos, J., \& Suckling, C. W. The Action of Fluothane: A New Volatile Anaesthetic. Brit. J. Pharmacol. 11: 394 (19.55).

3. Chang, J., McCartiey, H. H., \& Graves, H. B. Clinical Experience with Fluothane: A New Non-explosive Anaesthetic Agent. Canad. Anaesth. Soc. J. 4: 187 (1957).

4. Stephen, C. R.; Gross-Kreutz, D. C.; Lawrence, J. H. A.; Fabian, L. W.; BourgeorsGavardin, M.; \& Coughlin, Evaluation of Fluothane for Clinical Anaesthesia. Canad. Anaesth. Soc. J. 4: 246 (1957).

5. Epstenn, H. G., \& Macintosh, R. R. Anaesthetic Inhalers with Automatic Thermo-Compensation. Anaesthesia 11:83(1956).

6. Robson, J. C., \& WELT, P. The Concentrations of Fluothane Vapours Produced by Vapourizing Bottles of Some Standard Anae:thetic Machines. Canad. Anaesth. Soc. J. 4: 393 (1957).

7. McKax, I. M. A Clinical Evaluation of Fluothane with Special Reference to a Controlled Percentage Vapourizer. Canad. Anaesth. Soc. J. 4: 235 (1957).

8. Johnstone, M. The Human Cardiovascular Response to Flucthane Anaesthesia. Brit. J. Anaesth. 28: 392 ( 1957 ).

9. Macintosh, R. R., \& Mushin, W. IV. Physic:i for the Anaesthetist. Oxford: Blackwell Scientific Publications (1958). 